\title{
Effect of Three Methods of Morphological Awareness on Iranian Intermediate EFL Learners' Reading Comprehension
}

\section{Behnam Ghasemi}

Department of English, Isfahan (Khorasgan) Branch, Islamic Azad University, Isfahan, Iran, ghasemi.behnam@yahoo.com

\section{Mehdi Vaez-Dalili}

Department of English, Isfahan (Khorasgan) Branch, Islamic Azad University, Isfahan, Iran,mvaezdalili@yahoo.com

This study scrutinized the development of Iranian intermediate EFL learners' reading comprehension through the employment of three methods of morphological awareness (i.e. Textual Enhancement (TE), Metalinguistic Explanation (ME) and Morpheme Recognition Task (MRT). To do so, 90 intermediate EFL learners were divided into three groups, each group including 30 participants. Each group was taught sixty English derivational affixes including prefixes, suffixes and roots through three methods of morphological awareness (i.e., TE, ME, and MRT). Due to the high frequency of derivational affixes, less common derivational affixes were utilized for the treatment. For the purpose of the study, a pretest-posttest design was adopted. Given that it was impossible to provide texts containing all English affixes, single-sentence reading comprehension tests were administered as both pretest and posttest. As the first objective of the study, the development of the learners' morphological awareness in the three groups was measured by conducting a series of paired-samples $t$-tests. The results revealed that there was a significant improvement for all three groups. As another objective of the study, the posttest results of the reading comprehension test of the three groups were compared by running a one-way ANOVA.

Keywords: morphological awareness, textual enhancement, metalinguistic explanation, morpheme recognition task, single-sentence reading comprehension

\section{INTRODUCTION}

Morphological awareness refers to the ability to identify morphemes and morphological structure of words (Carlisle, 2003; Kuo \& Anderson, 2006). It takes account of the smallest meaningful units of language, including base words and affixes, which involve prefixes, suffixes, inflectional and derivational morphemes. Inflectional morphemes

Citation: Ghasemi, B., \& Vaez-Dalili, M. (2019). Effect of Three Methods of Morphological Awareness on Iranian Intermediate EFL Learners' Reading Comprehension. International Journal of Instruction, 12(2), 623-638. https://doi.org/10.29333/iji.2019.12239a 
make changes in base words depending on their time, number, or aspect (e.g., put to puts or book to books). Derivational morphemes, on the other hand, make changes in base words depending on their meanings, word class, or word clusters (e.g., happy to unhappy or sing to singer).

Kern (1989) argues that, unlike native speakers, second language learners are less likely to acquire word recognition automatically; hence, they have to give conscious attention to morphology. Kuo and Anderson (2006) put forward the idea that L2 learners who enjoy morphological knowledge including the knowledge of word formation through the combination of prefixes, suffixes, and roots, have command of more enriched vocabulary and enjoy better reading comprehension. According to Deacon and Kirby (2004), there exists a correlation between morphological awareness and reading comprehension.

Morphological awareness and reading, according to Kuo and Anderson (2006), have reciprocal and directional relationship and if being reciprocal, both morphological awareness and reading make contribution in improving each other and if directional, morphological awareness leads to reading proficiency, but the opposite is not possible. Based on what Graves, August, and Mancilla-Martinez (2013) stipulates, research reveals that the ability to diagnose and recognize morphological word families like vulgar, vulgarize, and vulgarization can be a skill in readings. The most remarkable contribution of morphological knowledge to reading is acknowledged to be in vocabulary meaning. As Nagy and Anderson (1984) claim, 60\% of the unknown words that a reader encounters in a text have meanings that can be imagined based on their constituent parts. Through better comprehension of word formation processes, a reader will be more empowered to guess the meanings of these words and will then manage to better work out the text (Nagy, Berninger, Abbott, Vaughan, \& Vermeulen, 2003).

Many inquiries have been done to explore the benefits of drawing on morphological awareness for learning word meaning (Raymond, Matti, \& Maria 2000), and therefore for enhancing vocabulary threshold (Sandra, 1994; Wysocki, \& Jenkins, 1987). As given in the literature, a plethora of studies (Carlisle, 1995; 2000; Carlisle \& Fleming, 2003; Deacon \& Kirby, 2004; Nagy, Berninger, \& Abbott, 2006) have been carried out on the role of morphological awareness in first language acquisition, whereas few explorations have examined the morphological awareness in second language learning. The present study departs from the previous studies in the literature by investigating the effect of three methods of morphological awareness (i.e. Textual Enhancement (TE), Metalinguistic Explanation (ME) and Morpheme Recognition Task (MRT)) on Iranian EFL learners' reading comprehension.

\section{LITERATURE REVIEW}

A number of empirical studies have inspected the relationship between morphological awareness and reading comprehension. A four-year longitudinal study, carried out by Deacon and Kirby's (2004), revealed that there is a positive relationship between morphological awareness and first language reading comprehension for the second, fourth and sixth graders. 
One study by Maag (2007) set out to examine morphological awareness and its association with young adults' first language reading abilities. The results of the study showed that explicit knowledge of morphological awareness is contributory to their reading comprehension. Moreover, it turned out that better L1 readers and those with more range of vocabulary had better metalinguistic awareness than less skillful readers.

Kieffer and Lesaux (2008) examined the relationship between morphological awareness and English reading comprehension among fourth and fifth grade Spanish-speaking English language learners. Learners' ability to analyse derived words while reading was tested utilizing an experimental task. The findings indicated that the relationship between morphological awareness and reading comprehension was strong between fourth and fifth graders, and in fifth graders, morphological awareness was a significant predictor of reading comprehension. Thus, the results supported the inclusion of derivational morphology in Spanish-speaking English language learners' English reading comprehension.

Siegel (2008) examined the relationship between morphological awareness and spelling and reading comprehension of children with dyslexia, typical readers, and young English language learners. The study demonstrated the contributory role of derivational morphology on learners' reading and spelling skills. Furthermore, the results confirmed that the learners with reading difficulties got lower scores than normal readers on the morphological awareness measure.

Ramirez, Chen, Geva, Kiefer (2010) examined within and cross-language effects of morphological awareness on word reading among 97 Spanish-speaking English language learners in grade 4 and grade 7 . Two measures of derivational morphology were conducted to evaluate morphological awareness in Spanish and in English. The results revealed that Spanish morphological awareness was contributory to Spanish word reading when other reading-related variables were controlled. English morphological awareness also explained unique variance in English word reading. Spanish to English cross-linguistic transfer of morphological awareness was observed, but not vice versa. The results indicated that morphological awareness was essential for word reading in Spanish. It also turned out that the development of morphological awareness in children's L1 (Spanish) was contributory to their L2 word reading (English).

Jeon (2011) examined the effect of second-language (L2) morphological awareness on foreign language reading comprehension. The participants of the study included 188 Tenth graders at a South Korean high school. They were judged on 6 reading- and language-related variables: phonological decoding, listening comprehension, vocabulary knowledge, passage-level reading comprehension, metacognitive reading awareness, and morphological awareness. The result showed that by controlling other variables, morphological awareness was contributory to L2 reading comprehension. The results of the study proved that morphological awareness, particularly derivational morphological knowledge, is a key variable in developing L2 reading comprehension among older readers. 
Pasquarella, Chen, Lam, Luo, and Ramirez (2011) explored cross-language transfer of morphological awareness in Chinese-English bilingual children. The participants of the study included 137 first to fourth graders. The tests of parallel measures of compound awareness, vocabulary, word reading and reading comprehension were administered to the children in Chinese and English. They were also given measures of English derivational awareness, English phonological awareness and nonverbal reasoning. The results suggested transfer of morphological awareness between Chinese and English. Above all, a bidirectional relationship between English compound awareness and Chinese vocabulary was evident. In addition, English compound awareness played an important role in improving Chinese reading comprehension.

Asgharzade, Rahimy, and Kalhor (2012) explored the impact of explicit morphological practice on developing EFL learners' reading comprehension. In their study, both the experimental and control groups were required to take reading comprehension test as the pretest. The test was designed to shed light on the effect of learners' morphological knowledge on their reading comprehension. Both groups received six sessions of reading comprehension treatment, but only the experimental one received the morphological practice during applying the treatments. The results of the posttest showed that participants in the experimental group gained a development in their reading comprehension ability.

Zhang and Koda (2013) scrutinized the effect of young Chinese EFL learners' morphological awareness on their reading comprehension. Inflection, derivation, as well as compounding morphological awareness were measured. Results indicated that the learners' inflectional awareness exceeded their derivational awareness. They were more successful in compound awareness than derivational awareness, and derivational awareness was superior to compound awareness. Besides, English reading comprehension was predicted by derivational and compound awareness in addition to the lexical and grammatical knowledge.

Deacon, Kieffer, and Laroche (2014) observed the relationship between morphological awareness and reading comprehension among elementary L2 students. Their findings made obvious that there is a bidirectional relationship between children's morphological awareness and reading comprehension. In other words, by raising the children's awareness of morphology, their reading comprehension was improved and concomitantly their reading comprehension development captured their progression in morphological awareness.

In another study conducted by Schano (2015), the effect of morphological knowledge on L2 reading comprehension was taken into account. The findings of her study proved that English morphological awareness, especially the derivational one, made a significant progress in L2 reading comprehension. It is also suggested that parallels in morphological awareness between L1 and L2 morphological structure be utilized and that morphological awareness be taught along with explicit vocabulary teaching.

Choi (2015) scrutinized the roles of L1 and L2 derivational morphological awareness of Korean EFL high school and university students in their L2 reading comprehension via 
the mediation of L2 vocabulary knowledge. Korean L1 and English L2 derivational morphological awareness and English L2 reading comprehension and vocabulary knowledge of 85 high school and 82 university students were measured. The findings of the research showed that there is a significant direct contribution of L2 derivational morphological awareness and L2 vocabulary knowledge to L2 reading comprehension. The results of the study demonstrated that L2 derivational morphological awareness played a more prominent role in L2 reading comprehension than L2 vocabulary knowledge.

Zhang (2016) elucidated the positive effect of morphological awareness among young Chinese readers. In his study, Zhang examined whether morphological awareness distinguished poor and good comprehenders. The study indicated that young Chinese learners with difficulties in reading showed weakness in all aspects of Chinese morphological awareness including derivation, lexical compounding, and compounding structure.

Deacon, Francis, and Tong (2017) examined the roles of morphological awareness and two skills of morphological analysis and morphological decoding in Grade 3 and Grade 5 children's reading comprehension. The results indicated that morphological awareness, morphological analysis, and morphological decoding contributed to reading comprehension. Meanwhile, the dimensions of morphological analysis and morphological decoding made an outstanding contribution to children's reading comprehension.

The issue of morphological awareness in L2 learning has not been extensively considered in the international research literature. While the domain of morphology has been very trendy in research on first language acquisition and the native mental lexicon, it has been mostly ignored in second language learning context (Sandra, 1997). Accordingly, this study aimed at exploring the influence of three types of morphological instructions (i.e. Textual Enhancement, Metalinguistic Explanation, and Morpheme Recognition Task) on the development of Iranian intermediate EFL learners' reading comprehension. To observe and fill the gaps in the literature, the study attempted to decipher the effect of implicit treatments (i.e. Textual Enhancement and Morpheme Recognition Task) versus the explicit one (i.e. Metalinguistic Explanation) on EFL learners' reading comprehension. To the best of the researchers' knowledge, no study has been conducted to investigate the effect of the above types of morphological instructions on the EFL learners' reading comprehension. Moreover, considering the literature, in most of the studies, only the most popular affixes are taken into account while in the current study it was endeavored to investigate the effect of less common morphological affixes on EFL learners' reading comprehension. Consequently, the current study sought to answer the following research questions:

1. Does each type of treatment (i.e. Textual Enhancement, Metalinguistic Explanation, and Morpheme Recognition Task) significantly affect the reading comprehension of Iranian intermediate EFL learners? 
2. Do the effects of the three types of treatments (i.e. Textual Enhancement, Metalinguistic Explanation, Morpheme Recognition Task) on the reading comprehension of Iranian intermediate EFL learners differ significantly?

\section{METHOD}

\section{Design}

In this study, as there was no true randomization, a quasi-experimental design with a quantitative method was utilized to collect and analyse the data. In order to cast light on the effect of three types of treatments, the pretest/posttest design was employed. In other words, this study aimed at finding out the effect of independent variables (i.e. Textual Enhancement, Metalinguistic Explanation, and Morpheme Recognition Task) on the dependent variable (i.e. reading comprehension). Furthermore, in order prevent practice effect, parallel pre- and posttests were used.

\section{Participants}

Since the study intended to explore the effect of three types of treatment on homogenized samples, the participants were selected from among a population of 200 undergraduate students majoring in Translation Studies at Islamic Azad University of Isfahan, Iran. As the focus of this research was on intermediate EFL learners, the Oxford Quick Placement Test (OQPT) was administered to the students in order to make sure about their level of English proficiency. Out of 120 intermediate students, 90 students were randomly selected and considered as the final participants of the study.

\section{Instruments}

\section{Oxford Quick Placement Test (OQPT)}

In order to make sure that all the participants under investigation enjoy the intermediate level of English language proficiency, version 1 of the Oxford Quick Placement Test (OQPT, 2001) was employed. The participants were required to take this 60 -item test in 30 minutes. Based on the rubric of the test for the score bands, scores between 0 to 29 are considered to be at the elementary level, scores that fall between 30 and 47 are taken to be at the intermediate level, and scores between 48 and 60 represent advanced proficiency level.

\section{Single-Sentence Reading Comprehension Test}

In order to measure the EFL learners' morphological knowledge and its impact on their reading comprehension, a single-sentence reading comprehension test was designed to be used as both the pre-test and posttest. The test involved 60 fill-in-the-blank and synonym-matching multiple-choice questions eliciting the learners' knowledge of 20 suffixes (e.g. -age, -some, -esque, -ee, -let, etc.), 20 prefixes (e.g. ir-, mal-, em-, para-, anti-, fore-, etc.) and 20 roots (i.e. astro, ped, chron, dorm, cred, etc.). Each test item was assigned 1 score; hence a maximum score of 60 .

Due to the fact that not all of the suffixes, prefixes, and roots chosen for the treatment could be included in a single authentic text, sentences rather than complete reading 
passages were used as the unit of instruction. In order to prevent the practice effect, the words included in the reading comprehension test were different from the words with the target prefixes, suffixes, and roots covered in the treatment. In other words, in order to avoid test-wiseness, the words with the target affixes and roots embedded in the sentences were not utilized in the single-sentence reading comprehension test.

The validity of the reading comprehension test was established through inviting the comments of one language testing and two language teaching experts on whether the items elicited what the study intended to measure. The reliability (i.e. internal consistency) of the test - calculated based on Cronbach's alpha - was reported to be .93 $(\alpha=.93)$.

\section{Materials}

To carry out the research, the less frequent and useful roots, prefixes, and suffixes embedded in sentences were taught via three different methods of morphological awareness (i.e. Textual Enhancement (TE), Metalinguistic Explanation (ME), and Morpheme Recognition Task (MRT)) in five consecutive sessions of treatment. Each session, the 20 roots, 20 prefixes, and 20 suffixes were taught to the three groups of participants. In other words, the three groups received the same affixes but with different methods of morphological awareness. Moreover, the selected roots, prefixes, and suffixes embedded in the sentences were the same in all five sessions of treatment but in different examples. Practically speaking, the participants in the TE group were taught the roots, prefixes, and suffixes embedded in the sentences via underlining and bold typing. In the ME group, the participants were given a list of the same roots, prefixes, and suffixes with explanations and their usages based on the book "Word Formation" by John Sinclair (1991). Finally, in the MRT group, the participants were required to analyse the underlined target words into their components and infer the meaning of each constituent without the help of the instructor.

\section{Procedures}

The initial cohort of participants $(n=90)$ was divided into three groups, each group consisting of 30 EFL learners. Prior to the treatment, they were asked to take the reading comprehension pretest

Due to the importance of derivational morphology, the focus of the treatment was on learning and teaching derivational morphology. To do so, each group of participants was taught derivational morphemes through a method of morphological awareness (i.e. Textual Enhancement, Metalinguistic Explanation, and Morpheme Recognition Task). For learning and teaching derivational morphology through textual enhancement (TE), the first group of EFL learners was required to be involved in five 20-minute sessions of learning derivational form of words. In each session, sixty affixed words were covered in such a way that derivational morphology was taught via a combination of highlighting and bolding-typing. The second group of participants was introduced the least frequent English suffixes, prefixes, and roots by the metalinguistic explanation (ME) method. Five sessions were needed to teach the morphemes and their meanings along with a few relevant examples. The 60 morphemes taught to the first group were also utilized for the 
second group. Finally, the third group of participants (i.e. morpheme recognition task (MRT)) were exposed to the same suffixes, prefixes, and roots as used for the first and second group of learners, but in this method, the learners themselves were asked to analyse the morphemes and write the meaning of the components of the target words.

In the last phase, the reading comprehension posttest was administered to make sure if there was a significant relationship between the learners' morphological awareness and their reading comprehension. Therefore, the same test utilized as the pretest was also employed as the posttest to divulge the difference.

\section{FINDINGS}

\section{Results of the Oxford Quick Placement Test (OQPT)}

As it was stated, to ensure that all of the participants in the study had the same level of English language proficiency prior to the treatment, the Oxford Quick Placement Test (OQPT) was administered. This test includes 60 items, with a score range of 0 to 60 . Based on the rubric of OQPT, the learners whose scores fell between 30 and 47 were considered to be at the intermediate level and were chosen as the research samples. In this study, 90 students were selected in order to take part in the treatment sessions. After assuring that all participants were homogenized so that they were all at the intermediate level of proficiency, 30 students were randomly assigned to the Textual Enhancement (TE) group, 30 students to the Metalinguistic Explanation (ME) group, and another 30 students to the Morpheme Recognition Task (MRT) group. The descriptive statistics for the scores of the participants in the three groups are illustrated in Table 1 below:

Table 1

Descriptive Statistics of OQPT Scores of the Three Groups of Participants

\begin{tabular}{lllll}
\hline Group & $\mathrm{N}$ & Mean & Std. Deviation & Variance \\
\hline Textual Enhancement (TE) & 30 & 42.96 & 2.68 & 7.18 \\
\hline Metalinguistic Explanation (ME) & 30 & 42.23 & 2.32 & 5.38 \\
\hline Morpheme Recognition Task (MRT) & 30 & 42.57 & 2.71 & 7.34 \\
\hline
\end{tabular}

As shown in Table 1, the TE $(X=42.96, \mathrm{SD}=2.68), \mathrm{ME}(X=42.23, \mathrm{SD}=2.32)$ and MRT $(X=42.57, S D=2.71)$ groups had nearly the same mean scores and standard deviations on the OQPT, suggesting that the three groups were homogenized before the treatment.

\section{Results of the First Research Question}

The first research question examined if the three type of treatment (i.e. TE, ME, and MRT) significantly affect the reading comprehension of Iranian intermediate EFL learners. Before analysing the relevant inferential statistics, the descriptive statistics (i.e. mean, standard deviation and variance) for the pretest and posttest scores of the three groups of participants are presented in Table 2 in the following: 
Table 2

Descriptive Statistics of the Pretest and Posttest Scores of the Three Groups of Participants

\begin{tabular}{llllll}
\hline Group & & $\mathrm{N}$ & Mean & Std. Deviation & Variance \\
\hline \multirow{2}{*}{ Textual Enhancement (TE) } & Pretest & 30 & 24.76 & 11.66 & 135.95 \\
\cline { 2 - 6 } Metalinguistic Explanation (ME) & Posttest & 30 & 36.84 & 7.45 & 55.50 \\
\hline \multirow{2}{*}{ Morpheme Recognition Task (MRT) } & Pretest & 30 & 25.65 & 10.87 & 118.16 \\
\cline { 2 - 5 } & Prettest & 30 & 43.72 & 7.25 & 52.56 \\
\cline { 2 - 5 } & Posttest & 30 & 31.61 & 7.81 & 128.14 \\
\hline
\end{tabular}

As indicated in the above table, the means of the three groups on the reading comprehension pretest were nearly the same (i.e. $24.76,25.65$, and 25.13 for the TE, $\mathrm{ME}$ and MRT groups respectively). However, the mean scores of all three groups showed a dramatic increase after the treatment, suggesting the effectiveness of the three types of treatment in all groups. However, in order to obtain rigorous statistical analysis regarding the improvement of the EFL learners, a set of inferential statistical procedures were used.

In order to investigate the impact of textual enhancement (TE) on the morphological awareness of the learners, a paired-samples t-test was conducted to compare the pretest and posttest scores of the TE group on the reading comprehension test (Table 3).

Table 3

Paired Samples T-Test Comparing the Pretest and Posttest Results of the Reading Comprehension Test of the TE Group

\begin{tabular}{|c|c|c|c|c|c|c|c|c|}
\hline & \multicolumn{5}{|c|}{ Paired Differences } & \multirow[b]{3}{*}{$\mathrm{t}$} & \multirow[b]{3}{*}{ df } & \multirow{3}{*}{$\begin{array}{l}\text { Sig. (2- } \\
\text { tailed) }\end{array}$} \\
\hline & \multirow[b]{2}{*}{ Mean } & \multirow{2}{*}{$\begin{array}{l}\text { Std. } \\
\text { Deviation }\end{array}$} & \multirow{2}{*}{$\begin{array}{l}\text { Std. Error } \\
\text { Mean }\end{array}$} & \multicolumn{2}{|c|}{$\begin{array}{l}\text { 95\% Confidence } \\
\text { Interval of the } \\
\text { Difference }\end{array}$} & & & \\
\hline & & & & Lower & Upper & & & \\
\hline $\begin{array}{l}\text { Pretest - } \\
\text { Posttest }\end{array}$ & -11.17 & 9.37 & 1.71 & -14.67 & -7.67 & -6.52 & 29 & .00 \\
\hline
\end{tabular}

The results indicate that there was a statistically significant difference between the pretest and posttest scores of the TE group on the reading comprehension test $(p<0.05)$. In other words, the textual enhancement technique could develop the learners' morphological awareness, and as a result, they achieved better scores on the singlesentence reading comprehension posttest.

In order to explore the impact of metalinguistic explanation (ME) on the morphological awareness of the learners, another paired-samples t-test was run to compare the pretest and posttest scores of the ME group on the reading comprehension test (Table 4). 
Table 4

Paired Samples T-Test Comparing the Pretest and Posttest Results of the Reading Comprehension Test of the ME Group

\begin{tabular}{|c|c|c|c|c|c|c|c|c|}
\hline & \multicolumn{5}{|c|}{ Paired Differences } & \multirow{3}{*}{$\mathrm{t}$} & \multirow{3}{*}{ df } & \multirow{3}{*}{$\begin{array}{l}\text { Sig. } \\
\text { tailed) }\end{array}$} \\
\hline & \multirow[b]{2}{*}{ Mean } & \multirow{2}{*}{$\begin{array}{l}\text { Std. } \\
\text { Deviation }\end{array}$} & \multirow{2}{*}{$\begin{array}{l}\text { Std. Error } \\
\text { Mean }\end{array}$} & \multicolumn{2}{|c|}{$\begin{array}{l}95 \% \text { Confidence } \\
\text { Interval of the } \\
\text { Difference }\end{array}$} & & & \\
\hline & & & & Lower & Upper & & & \\
\hline $\begin{array}{l}\text { Pretest - } \\
\text { Posttest }\end{array}$ & -16.83 & 8.91 & 1.62 & -20.16 & -13.50 & -10.35 & 29 & .00 \\
\hline
\end{tabular}

The results illustrate that there was a statistically significant difference in the reading comprehension posttest scores of Iranian intermediate EFL learners $(p<0.05)$. In other words, the learners' morphological awareness improved through the ME method.

As for the effect of the morpheme recognition task (MRT) on the morphological awareness of the EFL learners, a paired-samples t-test was conducted to compare their reading comprehension pretest and posttest scores. The results are presented in Table 5:

Table 5

Paired Samples T-Test Comparing the Pretest and Posttest Results of the Reading Comprehension Test of the MRT Group

\begin{tabular}{|c|c|c|c|c|c|c|c|c|}
\hline & \multicolumn{5}{|c|}{ Paired Differences } & \multirow{3}{*}{$\mathrm{t}$} & \multirow{3}{*}{$\mathrm{df}$} & \multirow{3}{*}{$\begin{array}{l}\text { Sig. (2- } \\
\text { tailed) }\end{array}$} \\
\hline & \multirow[b]{2}{*}{ Mean } & \multirow{2}{*}{$\begin{array}{l}\text { Std. } \\
\text { Deviation }\end{array}$} & \multirow{2}{*}{$\begin{array}{l}\text { Std. Error } \\
\text { Mean }\end{array}$} & \multicolumn{2}{|c|}{$\begin{array}{l}95 \% \text { Confidence } \\
\text { Interval of the } \\
\text { Difference }\end{array}$} & & & \\
\hline & & & & Lower & Upper & & & \\
\hline $\begin{array}{l}\text { Pretest - } \\
\text { Posttest }\end{array}$ & -7.80 & 8.18 & 1.49 & -10.87 & -4.74 & -5.22 & 29 & .00 \\
\hline
\end{tabular}

As can be seen in Table 5, there was a statistically significant difference in the reading comprehension pretest and posttest scores of the learners $(p<0.05)$. In other words, recognizing the derivational morphemes, the learners developed their awareness of various affixes and roots through the MRT method.

\section{Results of the Second Research Question}

The second research question investigated if there were significant differences in the effect of the three types of treatments (i.e. Textual Enhancement, Metalinguistic Explanation, Morpheme Recognition Task) on Iranian intermediate EFL learners' reading comprehension. As shown in Table 6, a one-way between-groups ANOVA was run to see if there were any statistically significant difference among the reading comprehension posttest scores of the TE, ME, and MRT groups: 
Table 6

One-way ANOVA Comparing the Posttest Results of the Reading Comprehension Test of the Three Groups

\begin{tabular}{llllll}
\hline & Sum of Squares & df & Mean Square & F & Sig. \\
\hline Between Groups & 261.67 & 2 & 130.83 & 2.31 & .03 \\
\hline Within Groups & 4918.33 & 87 & 56.53 & & \\
\hline Total & 5180.00 & 89 & & & \\
\hline
\end{tabular}

There was a statistically significant difference at the $\mathrm{p}<.05$ level in the reading comprehension test scores for the three groups: $\mathrm{F}(2,87)=2.31, \mathrm{p}=.03$. The effect size, calculated using eta squared, was .16 , showing a large relative magnitude of the differences between means. In order to exactly show where the differences among the three groups occur, a post-hoc Scheffe test was conducted, as represented in Table 7 in the following:

Table 7

Post-Hoc Scheffe Test Indicating the Exact Difference among the Posttest Scores of the Three Groups

\begin{tabular}{lllllll}
\hline & & Mean & & & \multicolumn{2}{c}{$95 \%$ Confidence Interval } \\
\cline { 5 - 7 } & & Difference & Std. Error & Sig. & Lower Bound & Upper Bound \\
\hline \multirow{2}{*}{ TE } & ME & $1.53^{*}$ & .81 & .00 & -.50 & 3.57 \\
\cline { 2 - 7 } & MRT & $3.67^{*}$ & .81 & .00 & 1.63 & 5.70 \\
\cline { 2 - 7 } & TE & $1.53^{*}$ & .81 & .00 & -3.57 & .50 \\
\hline \multirow{2}{*}{ MRT } & TE & $2.13^{*}$ & .81 & .03 & .10 & 4.17 \\
\cline { 2 - 7 } & ME & $2.67^{*}$ & .81 & .00 & -5.70 & -1.63 \\
\hline
\end{tabular}

*. The mean difference is significant at the 0.05 level.

Looking down the column labelled Mean Difference, we could see asterisks (*) next to some of the values listed. This means that the two groups being compared are significantly different from one another at the $p<.05$ level. The exact significance value is given in the column labelled Sig. Post-hoc comparisons using the Scheffe test indicated that the mean score for TE group $(\mathrm{M}=36.84, \mathrm{SD}=7.45)$ was significantly different from the mean score for the ME group $(M=43.72, S D=7.25)$ and the MRT group $(M=31.61, S D=7.81)$, and the mean score for the ME group $(M=43.72, S D=$ 7.25) was significantly different from the mean score for the MRT group ( $M=31.61$, $\mathrm{SD}=7.81)$.

\section{DISCUSSION AND CONCLUSION}

The main concern of this study was to figure out the effect of three methods of morphological awareness (i.e. Textual Enhancement, Metalinguistic Explanation, and Morpheme Recognition Task) on Iranian intermediate EFL learners' reading comprehension. It was also endeavoured to examine the superiority of implicit treatments (i.e. Textual Enhancement, Metalinguistic Explanation and Morpheme Recognition Task) versus explicit one (i.e. Metalinguistic Explanation) or vice versa. 
With respect to the first research question, it was found that the use of textual enhancement (TE) method, including underlining and bolding-typing was effective in such a way that the EFL learners improved in their single-sentence reading comprehension test. Another finding suggested that by utilizing the metalinguistic explanation (ME) method, the EFL learners could learn different prefixes, suffixes, and roots, as they got higher scores in their reading comprehension posttest than those of their pretest. The most interesting finding of the first research question referred to the impact of morpheme recognition task (MRT) through which the learners themselves had to recognize different affixes and roots and underline them. Perhaps it was the most unexpected finding because the EFL learners learned the morphemes without the help of the instructors. All in all, the findings revealed that the learners in all three groups did better in their reading comprehension posttest.

As evidenced in the literature, the findings of the first research question are in line with those of Asgharzade et al. (2012), who discerned that EFL learners' reading comprehension success owes to the practice of morphological awareness. The results of the present study are also consistent with that of Zhang and Koda (2013) who found out that young Chinese learners' reading comprehension improvement was brought about by their derivational awareness. These results accord with that of Choi (2015), who found that L2 derivational morphological awareness has a considerable contribution to L2 reading comprehension. The findings reflect those of Schano (2015), who also found that developing English morphological awareness structure, particularly derivational structure, make a substantial contribution to reading comprehension in L2. The results match those observed in another study conducted by Zhang (2016) with young Chinese readers in which it was shown that morphological awareness including derivation, lexical compounding, and compounding structure are contributory to distinguish poor comprehenders and good comprehenders. These results corroborate the ideas of Ramirez et al. (2010), who revealed that Spanish-English morphological awareness was helpful in developing Spanish-speaking children's word reading. In other words, this development was in favour of their both L1 (Spanish) and L2 (English). In addition, children's development of morphological awareness in L1 brought about a positive change in their L2 word reading. The findings of the present research are also in agreement with that of Pasquarella et al. (2011) which illuminated the significant and independent role of both types of morphological awareness (i.e. derivational as well as compound awareness) in Chinese immigrant children's English reading comprehension. These results further support Siegel's (2008) findings in which the contributory role of derivational morphology in improving reading comprehension of children with dyslexia, typical readers, and young English language learners was evident.

The results of the second research question, however, suggested that the posttest scores of the three groups (i.e. TE, ME, and MRT) were significantly different. In light of the findings of the current study, regarding the development of EFL learners' reading comprehension through morphological awareness, it was found that Metalinguistic Explanation (ME) made outstanding contribution to EFL learners' reading comprehension. Textual Enhancement (TE) and Morpheme Recognition Task (MRT) were in the second and third levels of importance respectively. In other words, the ME 
group outperformed the TE and MRT groups, and the TE group outperformed the MRT group (i.e. $\mathrm{ME}>\mathrm{TE}>\mathrm{MRT}$ ).

As mentioned earlier, the study also aimed at exploring the effectiveness of implicit treatments (i.e. Textual Enhancement and Morpheme Recognition Task) versus the explicit one (i.e. Metalinguistic Explanation) or vice versa in EFL learners' reading comprehension. As expected, it turned out that there was a significant difference between the three groups under investigation. It sheds light on the fact that Metalinguistic Explanation (ME), as an explicit method, was superior to the others in improving EFL learners' reading comprehension. This result is consistent with that of Maag (2007) who found out that one's explicit knowledge of morphological awareness is superior to the implicit knowledge.

The current study aimed at filling in the lacunae in the literature by finding out the effect of morphological awareness on second language learners' reading comprehension. However, most of the previous studies have explored the effect of morphological awareness on English monolinguals' (e.g., Carlisle, 1995; 2000; Carlisle \& Fleming, 2003; Deacon \& Kirby, 2004; Nagy et al., 2006) and young ESL learners' reading comprehension (e.g. Lam, Chen, Geva, Luo \& Li, 2012). The present study also adds to the body of literature by examining the effect of three different methods of morphological awareness on the learners' reading comprehension. Another point of departure in this study is the investigation of the effect of morphological awareness on learning less common affixes and roots.

Although the findings of the present study illuminated the significance of the morphological awareness on EFL learners' reading comprehension, there are some limitations in this regard. First, applying all 20 prefixes, 20 suffixes, and 20 roots in each session was time-consuming so that sometimes due to the lack of time and abundant material to cover, the process was tedious and slow. Second, since it was endeavoured to cover less common affixes and roots, finding a number of authentic context-based examples for some of the affixes and roots was demanding. Finally, thanks to the plethora of prefixes, suffixes and roots, it was unlikely to find passages to cover all prefixes, suffixes and roots. To address the shortcoming for data elicitation phase, single-sentence reading comprehension tests were employed.

In light of the findings of the present study, there are some pedagogical implications for teachers, syllabus designers, and lexicographers. By using implicit and explicit methods of teaching different morphemes, teachers should raise students' awareness to utilize less common affixes in order to be able to read and comprehend different texts with different levels of difficulty. In a similar vein, syllabus designers should take account of different techniques and tasks for raising EFL/ESL learners' morphological awareness. Moreover, lexicographers should also provide less common affixes embedded in different examples for the relevant dictionary entries.

The EFL/ESL teachers' main job is to provide lesson plans and teach in each session some specific affixes and roots via different methods of morphological awareness. Meanwhile, the students' primary responsibility is to practice the materials through 
reading different texts and concentrate on affixes and roots. Understanding morphological structure of words, especially the derivational structure of words, could be a contribution to learners' receptive and productive skills.

Future studies should assess the impact of morphological awareness on development of different language skills such as listening, speaking and writing. More research is required to account for the role of morphological structure of words in depth and breadth of vocabulary knowledge of EFL learners. Further research is also needed to better understand and compare the effect of derivational and inflectional morphological awareness on EFL learners' production and comprehension.

\section{REFERENCES}

Asgharzade, M., Rahimy, R., \& Pour Kalhor, O. (2012). The effect of explicit morphological practice on the reading comprehension abilities of Iranian intermediate level English language learners. Theory and Practice in Language Studies, 2(8), 16681677.

Carlisle, J. F. (1995). Morphological awareness and early reading achievement. In L. B. Feldman (Ed.), Morphological aspects of language processing (pp. 189-209). Hillsdale, NJ: Erlbaum.

Carlisle, J. F. (2000). Awareness of the structure and meaning of morphologically complex words: Impact on reading. Reading and Writing: An Interdisciplinary Journal, $12,169-190$.

Carlisle, J. F. (2003). Morphology matters in learning to read: A commentary. Reading Psychology, 24(3), 291-322.

Carlisle, J. F., \& Fleming, J. (2003). Lexical processing of morphologically complex words in the elementary years. Scientific Studies of Reading, 7, 239-253.

Choi, Y. H. (2015). Roles of L1 and L2 derivational morphological awareness in L2 reading through the mediation of L2 vocabulary knowledge. The Journal of Asia TEFL, 12(3), 81-114.

Deacon, S. H., \& Kirby, J. R. (2004). Morphological awareness: Just "more phonological"'? The roles of morphological and phonological awareness in reading development. Applied Psycholinguistics, 25, 223-238.

Deacon, S. H., Kieffer, M. J., \& Laroche, A. (2014). The relation between morphological awareness and reading comprehension: Evidence from mediation and longitudinal models. Scientific Studies of Reading, 18, 432-451.

Deacon, S. H., Francis, K., \& Tong, X. (2017). The relationship of morphological analysis and morphological decoding to reading comprehension. Journal of Research in Reading, 40(1), 1-16.

Graves, M. F., August, D., \& Mancilla-Martinez, J. (2013). Teaching vocabulary to English language learners. New York: Teachers College Press. 
Jeon, E. H. (2011). Contribution of morphological awareness to second-language reading comprehension. The Modern Language Journal, 95, 217-235.

Kern, R. (1989). Second language reading strategy instruction: Its effects on comprehension and word inference ability. The Modern Language Journal, 73(2), 135149 .

Kieffer, M. J., \& Lesaux, N. K. (2008). The role of derivational morphology in the reading comprehension of Spanish-speaking English language learners. Reading and Writing, 21, 783-804.

Kuo, L. J., \& Anderson, R. C. (2006). Morphological awareness and learning to read: A cross-language perspective. Educational Psychologist, 41, 161-180.

Lam, K., Chen, X., Geva, E., Luo, Y., \& Li, H. (2012). The role of morphological awareness in reading achievement among young Chinese-speaking English language learners: a longitudinal study. Reading and Writing: An Interdisciplinary Journal, 25, $1847-1872$.

Maag, L. K. (2007). Measuring morphological awareness in adult readers: Implications for vocabulary development. Unpublished doctoral dissertation, University of Florida, Florida.

Nagy, W. E., \& Anderson, R. C. (1984). The number of words in printed school English. Reading Research Quarterly, 19, 304-330.

Nagy, W., Berninger, V. W., \& Abbott, R. D. (2006). Contributions of morphology beyond phonology to literacy outcomes of upper elementary and middle-school students. Journal of Educational Psychology, 98, 134-147.

Nagy, W., Berninger, V., Abbott, R., Vaughan, K., \& Vermeulen, K. (2003). Relationship of morphology and other language skills to literacy skills in at-risk secondgrade readers and at-risk fourth-grade writers. Journal of Educational Psychology, 95, 730-742.

Pasquarella, A., Chen, X., Lam, K., Luo, Y. C., \& Ramirez, G. (2011). Cross-language transfer of morphological awareness in Chinese-English bilinguals. Journal of Research in Reading, 34(1), 23-42.

Ramirez, G., Chen, X., Geva, E. Kiefer, H. (2010). Morphological awareness in Spanish-speaking English language learners: within and cross-language effects on word reading. Reading \& Writing, 23, 337-358.

Raymond, B., Matti, L., \& Maria, V. K. (2000). The role of derivational morphology in vocabulary acquisition: Get by with little help from my morpheme friends. Scandinavian Journal of Psychology, 41(4), 287-296.

Sandra, D. (1994). The morphology of the mental lexicon: Internal word structure viewed from psycholinguistic perspective. Language and Cognitive Processes, 9, 227269. 
Sandra, D. (1997). Morphological awareness and the second language learner. In L. Vanlier, \& D. Corson (Eds.), Knowledge about language. Netherlands: Kluwer Academic Publishers.

Schano, L. (2015). The influence of morphological knowledge on L2 reading comprehension. Langues Et Linguistique, 35, 64-71.

Siegel, L. S. (2008). Morphological awareness skills of English language learners and children with dyslexia. Topics in Language Disorders, 28, 15-27.

Sinclair, J. (1991). Word formation. Glasgow: HarperCollins.

Wysocki, \& Jenkins, (1987). Deriving word meanings through morphological generalization. Reading Research Quarterly, 22, 66-81.

Zhang, D. \& Koda, K. (2013). Morphological awareness and reading comprehension in a foreign language: A study of young Chinese EFL learners. System, 41, 901-913.

Zhang, H. (2016). Development of morphological awareness in young Chinese readers: Comparing poor comprehenders and good comprehenders. Reading \& Writing Quarterly, 33(2), 187-197. 